NBER WORKING PAPER SERIES

\title{
MARKETPLACE PLAN PAYMENT OPTIONS FOR DEALING WITH HIGH-COST ENROLLEES
}

Timothy J. Layton

Thomas G. McGuire

Working Paper 22519

http://www.nber.org/papers/w22519

\author{
NATIONAL BUREAU OF ECONOMIC RESEARCH \\ 1050 Massachusetts Avenue \\ Cambridge, MA 02138 \\ August 2016
}

This research was supported by NIMH R01-MH094290 and the Laura and John Arnold Foundation. The authors are grateful to Savannah Bergquist, Jeannie Biniek, Michael Chernew, Michael Cohen, Kelly Drury, Randy Ellis, Jeff Grant, Laura Hatfield, John Hsu, Amanda Kreider, Joseph Newhouse, Cassandra Peitzman, Sherri Rose, Anna Sinaiko, Richard van Kleef, Rene van Vliet and Wynand van de Ven for helpful discussion. Jeannie Binniek and Amanda Kreider provided excellent research assistance. The views in this paper are the authors' own. The views expressed herein are those of the authors and do not necessarily reflect the views of the National Bureau of Economic Research.

NBER working papers are circulated for discussion and comment purposes. They have not been peer-reviewed or been subject to the review by the NBER Board of Directors that accompanies official NBER publications.

(C) 2016 by Timothy J. Layton and Thomas G. McGuire. All rights reserved. Short sections of text, not to exceed two paragraphs, may be quoted without explicit permission provided that full credit, including $\odot$ notice, is given to the source. 
Marketplace Plan Payment Options for Dealing with High-Cost Enrollees

Timothy J. Layton and Thomas G. McGuire

NBER Working Paper No. 22519

August 2016

JEL No. I11,I13,I18

\begin{abstract}
Two of the three elements of the ACA's "premium stabilization program," reinsurance and risk corridors, are set to expire in 2017, leaving risk adjustment alone to protect plans against risk of high-cost cases. This paper considers potential modifications of the HHS risk adjustment methodology to maintain plan protection against risk from high-cost cases within the current regulatory framework. We show analytically that modifications of the transfer formula and of the risk adjustment model itself are mathematically equivalent to a conventional actuarially fair reinsurance policy. Furthermore, closely related modifications of the transfer formula or the risk adjustment model can improve on conventional reinsurance by figuring transfers or estimating risk adjustment model weights recognizing the presence of a reinsurance function. In the empirical section, we estimate risk adjustment models with an updated and selected version of the data used to calibrate the federal payment models, and show, using simulation methods, that proposed modifications improve fit at the person level and protect small insurers against highcost risk better than conventional reinsurance. We simulate various "attachment points" for the reinsurance equivalent policies and quantify the tradeoffs of higher and lower attachment points.
\end{abstract}

Timothy J. Layton

Department of Health Care Policy

Harvard Medical School

180 Longwood Avenue

Boston, MA 02115

layton@hcp.med.harvard.edu

Thomas G. McGuire

Department of Health Care Policy

Harvard Medical School

180 Longwood Avenue

Boston, MA 02115

and NBER

mcguire@hcp.med.harvard.edu 


\section{Introduction}

By 2017, all state-level Marketplaces created by the Affordable Care Act (ACA 2010) will pay plans using the risk adjustment models and transfer formula developed by the Department of Health and Human Services (HHS). ${ }^{1}$ An effective plan payment system encourages the supply of efficient health insurance products and moves premiums close to competitive levels. It was recognized from the start in policy discussions that uncertainty about health care cost risk could limit insurer participation in Marketplaces and lead insurers (especially smaller issuers) to set high prices to protect themselves against cost risk. (Goodell, 2015; Kaiser Family Foundation, 2014) Although several years of claims experience can now guide issuers' decisions about entry and pricing, concerns about adequate supply and high prices persist. The market structure in many state Marketplaces is "highly concentrated" by conventional measures, even more so than insurance markets generally. ${ }^{2}$ Price levels in Marketplaces vary widely; higher average benchmark premiums are associated with fewer carriers in a state (PwC 2016). This suggests that policies that encourage entry by limiting insurer risk may be desirable.

During 2014-2016, three ACA “premium stabilization programs” were implemented with the intent of reducing cost uncertainty to plans: risk adjustment based on concurrent (within-year) diagnoses and demographics, mandatory transitional reinsurance for high-cost enrollees, and temporary risk corridors to limit plan-level losses. ${ }^{3}$ The goal of risk adjustment was to limit the structural problem of adverse selection, or the tendency of sicker consumers to choose certain plans. Reinsurance also limits adverse selection problems (Zhu et al. 2013, Layton, Ellis and McGuire. 2015), though its main purpose in this context was to complement the risk corridors to limit insurer

${ }^{1}$ The risk adjustment methodology, including the transfer formula, was established in the HHS Notice of Benefit and Payment Parameters for 2014 (2014 Payment Notice) (78 Federal Register 15410). This is the methodology used by HHS when operating risk adjustment on behalf of a state, with updates by benefit year in the applicable benefit year's Payment Notice. During 2014-16, Massachusetts was the only state with its own risk adjustment methodology. Massachusetts will transition to the federal system in 2017 (Massachusetts Health Connector). See CCIIO (2016) Chapters 1 and 2 for more discussion of the general methodology. 2 This is particularly true in areas where the number of issuers declined between 2014 and 2015. The Hirshman-Herfindahl Index (HHI) for the 208 counties that lost at least one issuer was 5,281 (ASPE 2015). $\mathrm{HHI}$ is the sum of squares of the market shares of firms in a market. An HHI above 2500 is usually considered "highly concentrated." This compares to an HHI of 3,888 for the individual market and 4,038 for the large group market in 2013 (Kaiser Family Foundation, 2013). In six states in 2016 (Alaska, West Virginia, Maine, South Dakota, Hawaii, and Oklahoma), only two issuers offer plans in the Marketplace; in one - Wyoming - only a single issuer is participating (ASPE 2016).

${ }^{3}$ The ACA included other features reducing adverse selection into the Marketplaces, including an individual mandate to participate and premium subsidies. Plans can also condition premiums on age and some other personal characteristics of enrollees that affect health costs, subject to regulation. 
risk and encourage entry and affordable pricing. In the design of the ACA, it was hoped that after an initial start-up phase, the subsidies and stabilization offered by reinsurance and risk corridors would no longer be necessary. In 2017, reinsurance and risk corridors are set to expire, exposing plans to new risk, particularly from high-cost cases, and also potentially worsening adverse selection problems in the market. This paper considers potential modifications of the HHS risk adjustment methodology, the only surviving stabilization policy after 2016, to both maintain plan protection against risk from high-cost cases within the current regulatory framework and limit adverse selection problems. Going forward, two elements of the risk-adjustment methodology can be used for this purpose: the transfer formula that uses the risk score and other factors to determine the redistributions among plans within a risk pool within a market within a state, and the risk adjustment model itself. We consider modifications to each of these two elements and demonstrate the following:

1. A modification of the transfer formula is mathematically equivalent to a conventional actuarially fair reinsurance policy;

2. A modification of the risk adjustment model is also mathematically equivalent to actuarially fair reinsurance;

3. Specific forms of these modifications protect plans better against risk than the current risk adjustment models and transfer formula plus reinsurance.

We support conclusions 1,2 and 3 analytically and empirically. The empirical work is based on the federal risk adjustment methodology and an updated version of data used to calibrate the model for the Marketplaces.

Modification of the transfer formula or the risk adjustment models can improve on the current system in two ways. First, these modifications reduce insurer costs, mimicking the effects of an actuarially fair reinsurance policy instead of the reinsurance policies in existence today that incorporate "loading" fees to cover administrative costs. Second, to date risk adjustment has been calibrated without regard to the presence of reinsurance. High-cost cases skew the distribution of spending for a group of individuals with a particular chronic condition, substantially driving up mean spending and, thus, the risk adjustment weight estimated for that group. When reinsurance compensates plans for high costs, the plan's average net liability for individuals with a particular chronic condition is reduced, implying that the risk adjustment weight should also be reduced. The current methodology for deriving risk adjustment weights ignores reinsurance, but this can be readily changed. Risk adjustment weights can be estimated, as we do below, taking compensation for high- 
cost cases into account and thereby be optimized for the costs needing risk adjustment, not costs covered by reinsurance (or its equivalent).

$\underline{\text { Policy and Research Background }}$

The Marketplace component of the ACA, nicknamed "Obamacare," remains controversial, in spite of its contribution to driving the rate of uninsured in the US to $11.0 \%$ in a recent Gallup poll of adults $18+.{ }^{4}$ This brief section focuses on the issue of plan supply in Marketplaces and the role of plan protection against risk from high-cost cases.

One hope implicit in the ACA was that the risk protection offered by the temporary risk corridors and transitional reinsurance programs would induce entry by small startup insurers lacking the initial capacity to self-insure against enrolling unexpectedly high cost individuals. While new insurers did enter many ACA marketplaces, by the end of 2015 a large portion of the largest group of these new insurers, the federally subsidized co-op plans, failed, despite more than $\$ 1 \mathrm{~b}$ in startup loans from the federal government (Armour, 2016). The National Alliance of State Health Co-ops blamed inadequacies of the risk adjustment and risk corridors programs. ${ }^{5}$ Moreover, some large legacy insurers are also exiting the Marketplaces, claiming similar issues: the CEO of United Healthcare, the largest insurer in the US, explained, "United Healthcare will leave most [state marketplaces] by 2017 because the markets for these exchanges are relatively small and also have higher risks for the company over the short-term."

The favorable properties of reinsurance in individual health insurance markets have been appreciated for some time (Swartz, 2006). Reinsurance likely encouraged entry and lowered initial prices in the Marketplaces. In interviews with the GAO $(2015,33)$, insurers participating in the Marketplaces cited reinsurance as positively influencing their entry decision, with some reporting that reinsurance was the most important of the premium stabilization programs. ${ }^{7}$ Industry analysts cite loss of reinsurance protection as a contributor to high anticipated premium increases for $2017 .{ }^{8}$

${ }^{4}$ The report is for the first quarter of 2016, and lowest recorded since initiation of this poll in 2008. See http://www.gallup.com/poll/190484/uninsured-rate-lowest-eight-year-trend.aspx. Accessed May 25, 2016. ${ }^{5} \mathrm{NASHCO}$, http://nashco.org/nashco-statement-on-recent-co-op-closures/. For a more extended critique of the ACA payment methodology from the standpoint of small plans, see CHOICES (2015).

${ }^{6}$ See (La Monica, 2016). United Healthcare, though a very large insurer, did not have a large presence in most Marketplaces. Its lack of participation rather than its exit has more of an effect on Marketplace competition.

${ }^{7}$ The GAO interviewed 12 issuers. Among the findings of the report with respect to reinsurance were: "Seven issuers said that the reinsurance program positively influenced their decision to participate in the 
Research shows that reinsurance is very effective at fitting individual-level plan payments to plan liabilities for high-cost cases using numerous data sets from the US, ${ }^{9}$ as well as in data from Germany (Schillo et al., 2016), the Netherlands (Van Barneveld et al., 1998, 2001), and Switzerland (Schmid and Beck, forthcoming), all with regulated individual health insurance markets sharing features with the Markeplaces. Schillo et al (2016) consider two options for dealing with high-cost cases in Germany: first, inclusion of up to three $(0,1)$ indicators of "high-cost groups" in the risk adjustment formula, and second, creation of a high-cost pool with partial reimbursement for a plan's costs above a threshold. The first is akin to what we consider here as a direction for modifying risk adjustment, and the second is equivalent to compulsory conventional reinsurance. A single dummy variable for a "funding gap above 30k Euros" in the regressions reported in Schillo et al (2016) increases the R-squared of the risk adjustment model from $27.6 \%$ to $51.0 \% .{ }^{10}$ A similar empirical approach was studied earlier in the Netherlands - including an indicator for exceeding a cost threshold in multiple past years as a risk adjustor (Van Kleef and Van Vliet, 2012), and subsequently included in the Dutch risk adjustment methodology. All of these studies show that reinsurance is a powerful tool for combatting adverse selection, suggesting that the removal of reinsurance may lead to new selection problems in Marketplaces.

individual market, including two issuers which described the reinsurance program as the most influential of the three risk mitigation programs on their decision to participate." With respect to premiums, "ten issuers [of the 12] said that the reinsurance program allowed them to offer lower premiums in 2014 and 2015." The reported reduction was in the range of 8 to 13 percent for 2014. The reduction was lower for 2015 because of the decrease in reinsurance coverage. GAO $(2015,33)$

${ }^{8}$ http://www.msn.com/en-us/money/healthcare/obamacare-sticker-shock-price-hikes-are-on-the-wav/arBBtnQ8N?li=BBnb7Kz\&ocid=iehp. Accessed May 24, 2016. Sections from this news article follow: "One of the underlying reasons for the big requests has to do with the expiration of the reinsurance program under the Affordable Care Act, which had served to offset some of the losses due to sicker customers who racked up high medical bills." "Without the program to offset losses, insurers are looking to reduce their risk and their losses in 2017," [according to one industry analyst].

${ }^{9}$ The following papers all use payment systems modelled on the Marketplaces. Geruso and McGuire (2016) use MarketScan data from 2008-09, and Zhu et al., (2013) and Layton, McGuire and Sinaiko (2016) use data from the Medical Expenditure Panel Survey (MEPS) with characteristics matching likely Marketplace participants. Using an updated version of the data used for calibration of the ACA risk adjustment models, the same data as are used in this paper, Layton, Ellis and McGuire (2015) show that reinsurance paired with prospective risk adjustment produces a fit of payments to costs much higher than concurrent risk adjustment with no reinsurance. Simulations in Layton, Ellis and McGuire (2015) assume that a prior year's data are unavailable for $50 \%$ of Marketplace participants and risk adjustment (as is done in Medicare for new enrollees) must be based only on age and gender. The reinsurance policy was $80 \%$ above $\$ 60 \mathrm{k}$.

${ }^{10}$ Schillo et al (2016) first compute the conventional risk adjusted payment, and compare this to cost to determine the "funding gap." 
Loss of mandatory reinsurance will also have a significant impact on the risk-reduction properties of the health plan payment system in the Marketplaces. In 2014, plans in the individual market received $\$ 7.9 \mathrm{~b}$ in reinsurance payments. (CCIIO, 2015) With the demise of the reinsurance and risk corridor policies, Marketplace insurers will face greater risk, potentially aggravating the problems of inadequate supply and pricing that are already present in some markets. Current risk adjustment policies capture averages conditional on risk factors but systematically underpredict costs for the high-cost cases most responsible for insurer risk. (CCIIO, 2016; Brown et al., 2014, Table 3)

It is unclear the degree to which privately purchased reinsurance can replace the public form, and at what price to insurers and, likewise, consumers. Informal interviews with representatives from reinsurers indicate that private reinsurance of the same form as public reinsurance with a higher attachment point is being purchased by Marketplace insurers. Use of brokers to solicit bids from reinsurers on behalf of insurers appears to be common. The National Alliance of State Health Co-Ops (NASHCO) lists a preferred broker on their website for private reinsurance. ${ }^{11}$ Alaska, a high-cost, low-competition market, is in the process of substituting state-level mandatory reinsurance for the departing federal version. ${ }^{12}$ We have been unable to find systematic information about pricing of reinsurance. It seems likely that with transaction costs and reinsurer profits, the ratio of expected payouts to insurers in relation to reinsurance premiums through the private market would be relatively low. By contrast, in our analysis, the set of policies we outline below are actuarially fair, in that they by definition require expected payments to insurers to be equal to expected payments from insurers. Such policies would thus improve on the status quo by eliminating the administrative costs of either a private or a conventional public reinsurance system.

\section{$\underline{\text { Plan of the Paper }}$}

Section 2 reviews the role of risk adjustment and the transfer formula in determining plan payments. Section 3 demonstrates the analytic equivalence between the current policy including reinsurance and specific modifications of the transfer formula and the risk adjustment models. We show this pair of equivalences for a general form of reinsurance defined by an attachment point (the level of costs where the reinsurance begins - sometimes referred to as a threshold) and a

\footnotetext{
${ }^{11}$ See $:$ http://nashco.org/preferred-vendors/

12 See: http://healthaffairs.org/blog/2016/06/16/alaska-reinsurance-plan-could-be-model-for-aca-reformplus-other-aca-developments /
} 
coinsurance (share of costs paid for by reinsurance above attachment). ${ }^{13}$ The exercise establishing equivalence points the way to improving on equivalence; that is, even without explicit reinsurance, the payment methodology can be modified through either the transfer formula itself or the risk adjustment models so as to provide a better fit of payments to costs than the current system. In the case of the transfer formula modification, this means decreasing the weight put on risk adjustment transfers in proportion to the share of costs not covered by reinsurance. In the case of risk adjustment, this means reoptimization of the risk adjustment weights to take account of costs covered by reinsurance. ${ }^{14,15}$

Section 4 begins the empirical work, using an updated version of the data used to calibrate risk adjustment in the individual and small group markets. We estimate risk adjustment weights and simulate transfer payments for four payment systems. The first is what we call the "current system" with risk adjustment and reinsurance figured separately. The second and the third are the modifications of the transfer formula and the risk adjustment models, respectively, which account for reinsurance in the ways noted above. Within each of these payment alternatives we study four alternative attachment points: $\$ 2 \mathrm{~m}, \$ 1 \mathrm{~m}, \$ 500 \mathrm{k}$ and $\$ 100 \mathrm{k}$, all with an $80 \%$ coinsurance. The fourth payment system is risk adjustment without reinsurance, the default policy for 2017 and beyond. We measure payment system performance with respect to the ability to combat adverse selection problems in Section 4 with "payment system fit," a generalization of the R-squared measure for a risk adjustment regression which takes account of the full set of mechanisms transferring funds to match costs at the person level, and allows us to compare payment systems using a combination of risk adjustment and cost-sharing features. ${ }^{16}$ Adding a reinsurance equivalent through either route of modification (as well as through a conventional reinsurance policy) substantially improves payment system fit. The payment system fit with the default policy for 2017 , risk adjustment only, is .44.

\footnotetext{
${ }^{13}$ Note that this "coinsurance" is the opposite of the traditional definition of coinsurance. Here, the reinsurer reimburses at the coinsurance rate. Traditionally, the insured pays the coinsurance rate and the insurer reimburses at one minus the coinsurance rate.

${ }^{14}$ Currently, risk adjustment weights are estimated via a regression of gross (including dollars covered by reinsurance) spending on the risk adjustor variables. By "reoptimization" to take account of costs covered by reinsurance, we mean estimating risk adjustment weights via a regression of net (of reinsurance) spending on the risk adjustor variables.

15 In practice, "reoptimized" risk adjustment weights could be used in the modified transfer formula case as well, improving the fit of that payment system. To contrast these two different approaches we do not do this here, using the original risk adjustment weights with the modified transfer formula.

${ }^{16}$ For a detailed explanation of payment system fit and its relevance in this context, see Layton, Ellis, and McGuire (2015).
} 
Modifying either the transfer or risk adjustment specification to incorporate the reinsurance function raises the fit to .50 with an attachment point of $\$ 1 \mathrm{~m}$ and to .57 with an attachment point of $\$ 500 \mathrm{k}$.

Section 5 studies the implications of the payment alternatives for insurers, conducting a series of insurer-level Monte Carlo simulations on a measure of the "risk of ruin" (we choose the probability an insurer gets a draw of enrollees resulting in a loss of greater than $5 \%$ of revenues) for insurers of various sizes (20k, $10 \mathrm{k}$ and $5 \mathrm{k}$ enrollees) under the alternative payment methodologies. ${ }^{17}$ Again, modifying either the transfer or the risk adjustment models in the way we propose decreases the risk of ruin substantially, particularly for smaller insurers. For example, an insurer with 10k members runs a risk of ruin of $5.3 \%$ due to a random draw from the population with risk adjustment only. This falls to $4.3 \%$ with an attachment point of $\$ 1 \mathrm{~m}$ with either the transfer formula or risk adjustment model modification and to $3.0 \%$ and $3.1 \%$ for an attachment point of $\$ 500 \mathrm{k}$ with modification of the transfer formula or risk adjustment model, respectively.

Section 6 discusses the advantages and disadvantages of the transfer formula and risk adjustment model approaches, and considerations around the choice of the attachment point/reinsurance combinations. Throughout the paper, we use the term "plan" to refer to a particular benefit option in the individual health insurance market (e.g., a particular Silver plan) and "insurer" to refer to the company offering the plan. An insurer (sometimes referred to as an “issuer”) may offer many plans.

\section{Health Plan Payment in the Marketplaces}

ACA compliant plans in the individual and small group markets collect the premiums they set, which can be conditioned, subject to regulation, on acturarial value, age, family structure, smoking status, and region. These plans also receive a risk adjustment transfer, which can be positive or negative, intended to adjust for the relative health care cost risk of the plans' enrollees in relation to the state average. (Pope et al., 2014) A plan's risk adjustment payment or charge is

\footnotetext{
${ }_{17}$ One could argue that the "risk of ruin" threshold of 5\% and the plan sizes of 5k-20k seem small. The small plan sizes were chosen due to the fact that reinsurance is intended to protect small insurers from risk. Large insurers are assumed to be able to "self-insure" due to their large numbers of covered lives. The risk of ruin threshold of $5 \%$ is likely relevant for these small insurers. This threshold also produces non-trivial risk of bankruptcy in our simulations in order to more clearly illustrate the differential effects of the various payment systems. While the actual risks would not be the same for larger thresholds, differences in risk across payment systems, the focus of this paper, would remain similar.
} 
determined by the difference between a plan's predicted required revenues based on its enrollees' health status and the premium revenue it can be expected to collect based on its enrollees' allowable premium rating factors (e.g., age categories). As described in CCIIO $(2016,80)$ :

"The purpose of risk adjustment transfers is to provide plans with enough additional revenue to cover their actual risk exposure beyond the premiums they are able to collect, or in other words, to compensate for excess actuarial risk due to risk selection. Conceptually, the transfer formula measures the difference between:

- the revenues required by a plan given the health status expenditure risk of the plan's actual enrollees; and

- the revenues that a plan can generate based on the allowable rating factors of the plan's actual enrollees."

Adjustments for a plan's actuarial value (metal level), allowable differences due to premium categories, and geographic cost factors in relation to the state average also figure into the transfer formula. We abstract from these features in this paper in order to focus on health status risk adjustment and high-cost cases.

The Health and Human Services-Hierarchical Condition Categories (HHS-HCC) risk adjustment model uses an individual's demographics and selected diagnoses to determine a risk score meant to predict health cost risk to a plan. The HHS-HCC model, based on the model used to pay Medicare Advantage plans in Medicare, is modified to take account of the younger population, different covered benefits, and higher turnover rates in Marketplaces. Notably, the HHS-HCC model is concurrent, basing the risk score on the current year's diagnoses. ${ }^{18}$ The HHSHCC model is designed to predict plan liability (as opposed to total costs), and slightly different model coefficients are used for the various plan metal levels. Risk adjustment weights on the demographic factors and concurrent diagnoses are estimated coefficients from an ordinary least squares (OLS) regression. ${ }^{19}$

The reinsurance program for 2016 reimburses a plan for 50\% of an enrollee's annual spending above an attachment point of $\$ 90 \mathrm{k}$ up to a cap of $\$ 250 \mathrm{k}$. The share of plan costs covered by reinsurance decreased over the three-year transitional period, 2014-16. In 2014, the reinsurance attachment point was $\$ 45 \mathrm{k}$ with a coinsurance of $100 \%$. (CCIIO, 2015) The program is financed by a contribution rate set in the applicable benefit year Payment Notice and assessed on all covered

\footnotetext{
18 The model used for Medicare Advantage plans (and most other risk adjustment applications in other countries) is prospective, basing risk score this year on diagnoses received last year.

${ }^{19}$ See Kautter et al. (2014) for details. Some of the weights are modified post-estimation from the regression coefficients to ensure monotonicity according to clinical severity graduations within diagnostic groupings.
} 
lives under all fully insured health insurers and certain self-funded insurers that offer major medical coverage. $^{20}$ The current reinsurance program represents a net subsidy into Marketplace plans and is run nationally. The analytical version of reinsurance we consider next is balanced budget within a state. We comment on national versus state-level policy at the close of the paper.

\section{Analytic Properties of Alternatives for Dealing with High-Cost Cases}

Consider a plan with state average values for actuarial value, size, population characteristics affecting premiums, and geographic cost factors. In this case, the transfer the plan receives/pays depends only on the health status of the plan's population as measured by the risk adjustment formula in relation to the state average, and can be written as follows:

$$
\mathrm{T}_{\mathrm{i}}=\left(\frac{\mathrm{R}_{\mathrm{i}}}{\overline{\mathrm{R}}}-1\right) \overline{\mathrm{P}}
$$

$\mathrm{T}_{\mathrm{i}}$ is the transfer (+/-) to plan $\mathrm{i}, \mathrm{R}_{\mathrm{i}}$ is the average risk score among plan i's enrollees, and $\overline{\mathrm{R}}$ and $\overline{\mathrm{P}}$ are state average values for the risk score and premium, respectively. For this analysis, we measure risk scores in dollars and assume competitive pricing, so that $\bar{R}=\bar{P} .{ }^{21} T_{i}$ is positive when plan i's risk score exceeds the state average, and negative when it falls below. Transfers in (1) sum to zero in aggregate as they must in the risk pool, since the sum of $\frac{R_{i}}{\bar{R}}-1$ over the i plans weighted by plan size is 0 . All transfer and risk adjustment modifications considered in this paper retain this balanced-budget property.

For purposes of comparison with modifications of the transfer formula and risk adjustment models, we introduce an actuarily fair reinsurance system (i.e., with no loading fees) financed by premiums paid by plans. Let $\mathrm{HC}_{\mathrm{i}}$ represent costs in plan $\mathrm{i}$ above the attachment point (thereby eligible for reinsurance) and let " $a$ " be the share paid by the reinsurer above the attachment point, referred to in the reinsurance world as the "coinsurance rate." Plan i receives reinsurance payments $\mathrm{aHC}_{\mathrm{i}}$. The balanced budget premium each plan must pay to finance these payments is $\mathrm{a} \overline{\mathrm{HC}}$ where $\overline{\mathrm{HC}}$ is the plan average of costs above the attachment point across all plans in the state. The net reinsurance payment to plan $\mathrm{i}$ is $\mathrm{RE}_{\mathrm{i}}$ and is expressed as follows:

${ }^{20}$ In 2016 the reinsurance premium was equal to $\$ 27$ annually per covered life (2016 Notice of Benefit and Payment Parameters, 80 Federal Register 10750).

${ }^{21}$ This is a normalization and an assumption. The normalization is to the risk scores so that $\bar{R}=\bar{C}$, where $\bar{C}$ is average cost, and the assumption is that the average premium is equal to average cost, $\overline{\mathrm{P}}=\overline{\mathrm{C}}$, as it would be under perfect competition. 


$$
\mathrm{RE}_{\mathrm{i}}=\mathrm{aHC}_{\mathrm{i}}-\mathrm{a} \overline{\mathrm{HC}}
$$

Net reinsurance payments sum to zero at the state level.

In what we will refer to as the "current system" in which risk adjustment and reinsurance both apply, the net payment to plan $\mathrm{i}$ is the sum of the risk adjustment transfers and the net reinsurance payment, which we call $\mathrm{Y}_{\mathrm{i}}$ :

$$
\mathrm{Y}_{\mathrm{i}} \equiv \mathrm{T}_{\mathrm{i}}+\mathrm{RE}_{\mathrm{i}}=\left(\frac{\mathrm{R}_{\mathrm{i}}}{\overline{\mathrm{R}}}-1\right) \overline{\mathrm{P}}+\mathrm{aHC} \mathrm{i}_{\mathrm{i}}-\mathrm{a} \overline{\mathrm{HC}}
$$

\section{Modifying the Transfer Formula}

We first consider modifying the transfer formula, leaving risk adjustment $\left(\mathrm{R}_{\mathrm{i}}\right)$ intact. The purpose is to show there is a modification of $T_{\mathrm{i}}$ without explicit reinsurance that is equivalent to (3).

Rewrite the net reinsurance payment from (2) as:

$$
\mathrm{RE}_{\mathrm{i}}=\mathrm{a} \overline{\mathrm{P}} \frac{\overline{\mathrm{HC}}}{\overline{\mathrm{P}}} \frac{\mathrm{HC}}{\overline{\mathrm{HC}}}-\mathrm{a} \overline{\mathrm{P}} \frac{\overline{\mathrm{HC}}}{\overline{\mathrm{P}}}
$$

Total net plan payment in the current system can then be expressed as:

$$
Y_{i}=\left(\frac{R_{i}}{\bar{R}}-1\right) \bar{P}+\left(\frac{H_{i}}{\overline{H C}}-1\right) \bar{P} \frac{a \overline{H C}}{\bar{P}}
$$

Regrouping, we define $\mathrm{T}_{\mathrm{i}}^{\mathrm{RE}}$, a transfer formula incorporating reinsurance.

$$
\mathrm{T}_{\mathrm{i}}^{\mathrm{RE}}=\left(\frac{\mathrm{R}_{\mathrm{i}}}{\overline{\mathrm{R}}}-1+\frac{\mathrm{a} \overline{\mathrm{HC}}}{\overline{\mathrm{P}}}\left(\frac{\mathrm{HC}_{\mathrm{i}}}{\overline{\mathrm{HC}}}-1\right)\right) \overline{\mathrm{P}}
$$

The modified transfer formula (4) supplements the present transfer based on risk adjustment proportional to $\frac{\mathrm{R}_{i}}{\overline{\mathrm{R}}}-1$ with another component in the same spirit, $\frac{\mathrm{HC}_{\mathrm{i}}}{\overline{\mathrm{HC}}}-1$, the excess of high costs at plan $\mathrm{i}$ in relation to the state average. The importance of this additional transfer component is weighted by the share of reinsurance payments in a state in relation to the premium, $\frac{\mathrm{a} \overline{\mathrm{HC}}}{\overline{\mathrm{P}}}$. With competitive pricing, average premium is equal to average costs, and the weight is the share of costs to which reinsurance is applied.

Transfer formula $\mathrm{T}_{\mathrm{i}}^{\mathrm{RE}}$ in (4) is exactly equivalent to the current payment system of risk adjustment transfers and reinsurance figured separately. Note that because we required the current reinsurance system to be actuarially fair, $\mathrm{T}_{\mathrm{i}}^{\mathrm{RE}}$, is in fact better than both the true current system and 
private reinsurance in that it provides the same risk protection without the administrative and loading costs of those alternative systems.

It is possible to take account of reinsurance within the modifying-the-transfer-formula approach by weighting the risk adjustment component of the transfer, $\frac{R_{i}}{\bar{R}}-1$, by the share of costs to which reinsurance does not apply, $1-\frac{\mathrm{a} \overline{\mathrm{HC}}}{\overline{\mathrm{P}}}$. Applying this weight to the risk adjustment component and substituting $\overline{\mathrm{R}}$ for $\overline{\mathrm{P}}$, we get a modified transfer formula, $\widetilde{\mathrm{T}}_{\mathrm{i}}^{\mathrm{RE}}$ :

$$
\begin{aligned}
& \widetilde{\mathrm{T}}_{\mathrm{i}}^{\mathrm{RE}}=\left(\left(1-\frac{\mathrm{a} \overline{\mathrm{HC}}}{\overline{\mathrm{R}}}\right)\left(\frac{\mathrm{R}_{\mathrm{i}}}{\overline{\mathrm{R}}}-1\right)+\frac{\mathrm{a} \overline{\mathrm{HC}}}{\overline{\mathrm{R}}}\left(\frac{\mathrm{HC}_{\mathrm{i}}}{\overline{\mathrm{HC}}}-1\right)\right) \overline{\mathrm{P}} \\
& \widetilde{\mathrm{T}}_{\mathrm{i}}^{\mathrm{RE}}=\left(\left(1-\frac{\mathrm{a} \overline{\mathrm{HC}}}{\overline{\mathrm{R}}}\right)\left(\frac{\mathrm{R}_{\mathrm{i}}}{\overline{\mathrm{R}}}\right)+\frac{\mathrm{a} \overline{\mathrm{HC}}}{\overline{\mathrm{R}}}\left(\frac{\mathrm{HC}_{\mathrm{i}}}{\overline{\mathrm{HC}}}\right)-1\right) \overline{\mathrm{P}}
\end{aligned}
$$

The modification in (4') uses weights on the risk adjustment and high-cost factors to take account of the interaction of risk adjustment and reinsurance. We refer to (4') as the "modified transfer formula." (4') is the transfer formula we will simulate empirically in Sections 4 and 5.

\section{Modifying Risk Adjustment}

We next consider a modification of $\mathrm{R}_{\mathrm{i}}$, the risk adjustment model for the same purpose, to find a form that reproduces plan payments in the current system (3). To do so, rewrite the net reinsurance payment from (2) as:

$$
\mathrm{RE}_{\mathrm{i}}=\frac{\left(\mathrm{aHC} \mathrm{i}^{-}-\mathrm{a} \overline{\mathrm{HC}}\right)}{\overline{\mathrm{R}}} \overline{\mathrm{P}}
$$

Total net plan payment in the current system is then:

$$
Y_{i}=\left(\frac{\left(R_{i}+a H C_{i}-a \overline{H C}\right)}{\bar{R}}-1\right) \bar{P}
$$

The modified risk adjustment model $\mathrm{R}_{\mathrm{i}}+\mathrm{aHC}_{\mathrm{i}}-\mathrm{a} \overline{\mathrm{HC}}$ produces a transfer payment equivalent to the original risk adjustment model plus reinsurance. The modified risk adjustment in (3") has a natural interpretation. We add a "risk factor" of current-year spending for each individual to the risk adjustment formula, and assign this risk factor a "coefficient" of a. We then deduct a⿳亠丷厂 from the constant term in $\mathrm{R}_{\mathrm{i}}$ (to finance the reinsurance payments).

We can take this modification another step. The risk score, $\mathrm{R}_{\mathrm{i}}$, in (3") was from the current system in which risk adjustment weights were estimated independently from reinsurance (i.e. via a regression of gross of reinsurance spending on risk adjustors). We can instead estimate new risk 
scores from a regression that pulls out the costs reimbursed by reinsurance prior to estimation (i.e. via a regression of net of reinsurance spending on risk adjustors). Call this reoptimized risk adjustment $\mathrm{R}_{\mathrm{i}}^{\mathrm{RE}}$ (for risk adjustment accounting for reinsurance). Then, the improved modification via risk adjustment is:

$$
\mathrm{Y}_{\mathrm{i}}^{\mathrm{RE}}=\left(\frac{\left(\mathrm{R}_{\mathrm{i}}^{\mathrm{RE}}+\mathrm{aHC} \mathrm{C}_{\mathrm{i}}\right)}{\overline{\mathrm{R}}}-1\right) \overline{\mathrm{P}}
$$

OLS ensures that $Y_{i}^{R E}$ is balanced budget. Note that the $-\mathrm{a} \overline{\mathrm{HC}}$ term is no longer necessary. The OLS regression will adjust the constant term in the model such that the new risk score, $R_{i}^{R E}$, ensures balanced budget risk adjustment transfers. We refer to (3") as "modified (reoptimized) risk adjustment." We estimate and simulate (3"”) in Sections 4 and 5.

\section{Data and Empirical Methods}

This section describes the data and the methods we use to estimate risk adjustment models and conduct simulations. In practice, the HHS risk adjustment methodology uses separate risk adjustment models for different metal levels and population age groups. We illustrate the empirical properties of risk adjustment with one adult model estimated for the 21-64 population.

$\underline{\text { Data }}$

We use an updated version of the health insurance claims data used by Kautter et al. (2014) to develop the HHS-HCC Marketplace payment system, the Truven MarketScan Commercial Claims and Encounters dataset (MarketScan). Kautter et al. (2014) used data from 2010; we use 2013. Following criteria applied for estimation of the 2014 HHS-HCC model, we keep individuals enrolled in a preferred provider organization (PPO) or other fee-for-service (FFS) health plan in both the first and last months of the data, ${ }^{22}$ and who have no payments made on a capitated basis (Kautter et al., 2014). Also, following HHS criteria, we require individuals to have both mental health and drug coverage. We exclude the few individuals who have claims with negative payments. After applying the inclusion and exclusion criteria, we have one full year of claims for 7,072,964 individuals.

22 Other FFS plans include Exclusive Provider Organization, Non-Capitated Point-of-Services, ConsumerDriven Health Plan, and High-Deductible Health Plan. 
As is well-known, consumers in the MarketScan data mostly have coverage through their employers and are not eligible for participation in Marketplaces. Our sample differs from that used in Kautter et al (2014) in that we select a subset of MarketScan enrollees more likely to reflect the patterns of health care used by Marketplace enrollees. From the $7.1 \mathrm{~m}$ sample, we select a subsample chosen to more closely reflect the age, gender, geography and disease characteristics of people eligible for coverage in the ACA Marketplaces. ${ }^{23}$ We anticipate that the selected sample of 2,006,126 people, will improve calibration of risk adjustment models and yield more valid simulations of likely Marketplace payment/cost comparisons. Our selected sample is slightly younger and more frequently from the South and West region than the unselected MarketScan data. ${ }^{24}$ Among the advantages of this sample is that because we incorporate MEPS sample weights in the matching, it is nationally representative of potential Marketplace enrollees and can be used for estimation and simulation without further weighting.

Estimating Risk Adjustment Models

We first estimate a concurrent risk adjustment model using the HHS-HCC specification and HHS software to generate HHS-HCCs for our population of enrollees. ${ }^{25}$ These HCCs along with a set of age-sex cells also included in the HHS-HCC risk adjustment model make up the risk adjustment variables. Weights are estimated via a regression of total 2013 spending on risk adjustors, and reported in a table in the Appendix. ${ }^{26}$ This first model corresponds to $\mathrm{R}_{\mathrm{i}}$ from (1).

We also estimate the modified risk adjustment model that incorporates the function of reinsurance, corresponding to $\mathrm{R}_{\mathrm{i}}^{\mathrm{RE}}$ from (3"'). One way to do this would be to literally pull out costs

${ }^{23}$ We select this subset from MarketScan using methods from earlier work using the Medical Expenditure Panel Survey (MEPS) to define persons with the characteristics that would make them eligible for the Marketplace (McGuire et al., 2013, 2014), and propensity model methods within MEPS using variables common to MEPS and MarketScan (Rose et al., forthcoming). In essence we estimate the propensity an observation in MEPS is Marketplace eligible (in relation to large group health insurance) and then use this propensity score, along with nationally representative population weights from MEPS to draw a sample from MarketScan.

${ }^{24}$ See Layton, Ellis and McGuire (2015, Table 3) which compares the selected and unselected MarketScan samples.

${ }^{25}$ Software can be found at https://www.cms.gov/CCIIO/Resources/Regulations-andGuidance/Downloads/SAS-Software-October-2015.zip. For simplicity, we do not impose constraints on the coefficients as was done by Kautter et al (2014) to ensure monotonicity within each hierarchy and nonnegative coefficients.

${ }^{26}$ While the actual weights used in the Marketplaces are publicly available, we estimate the weights relevant for our selected sample. New weights on updated data will be used going forward in Marketplace risk adjustment models. In other research we have compared our estimates to the publicly available weights in simulations, and there is little difference in results. See Layton, Ellis and McGuire (2015). 
covered by reinsurance prior to estimation. For example, if the attachment point were $\$ 500 \mathrm{k}$ and the coinsurance were $80 \%$, pull out $80 \%$ of costs over $\$ 500 \mathrm{k}$ and then estimate. We estimate $\mathrm{R}_{\mathrm{i}}^{\mathrm{RE}}$ in an equivalent and simpler way more closely corresponding to the analysis in Section 3. Specifically, we add a variable to the risk adjustment model equal to "costs above the attachment point" and constrain the coefficient ("a" from Section 3) on this variable to be .8. In the case of a $\$ 500 \mathrm{k}$ attachment point, if a person spends less than $\$ 500 \mathrm{k}$, the value of this variable is zero. If a person spends above, for example, $\$ 532 \mathrm{k}$, the value would be $\$ 32 \mathrm{k}$. Note that a separate risk adjustment model will need to be estimated for each attachment point studied. It would be possible of course to omit the restriction that the coefficient be equal to .8 and allow "a" to be estimated along with the other coefficients in the modified risk adjustment formula. This would be undesirable for two reasons: first, an estimated coefficient different than .8 would defeat the purpose of substituting precisely for a particular form of reinsurance, and second, the estimated coefficient on "a" is likely to be greater than 1.0, introducing unacceptable incentive properties in the payment system. ${ }^{27}$ Restricting the coefficient to .8 in an OLS regression is a one-line modification of the SAS code. Evaluating Payment Alternatives: Payment System Fit at the Person Level

We use two measures to compare the alternative payment systems. The first measure captures how well the payment system deals with adverse selection problems. Comparison of the payment alternatives requires a measure that incorporates the contribution of reinsurance as well as risk adjustment. Payment system fit is a statistic that has been shown to measure payment system performance with respect to adverse selection problems. ${ }^{28}$ Payment system fit captures the full fit of a payment system in terms of matching payments to actual costs at the person level, and can incorporate the role of premiums, risk adjustment, and reinsurance as well as other forms of cost sharing. Payment system fit measures the explained variance in costs accounted for by risk adjustment and reinsurance -- not just the variance explained by the risk adjustment model.

\footnotetext{
${ }^{27}$ The incentive problems stem from the fact that a coefficient above 1.0 implies that, above the threshold, for each additional dollar that an insurer spends, it receives back more than one dollar via risk adjustment. The reason for the estimated coefficient greater than 1.0 is that even after reinsurance payments, high-cost cases still have costs higher than predicted with the conventional risk adjustor variables. The unrestricted estimated coefficient on $\mathrm{HC}$ reflects the correlation of $\mathrm{HC}$ with these "losses," moving the estimated coefficient above 1.0. The unrestricted estimate of the coefficient on HC at $\$ 100 \mathrm{k}$ and the HHS-HCC risk adjustment specification is 1.4 .

${ }^{28}$ See Geruso and McGuire (2016), Layton Ellis and McGuire (2015) where payment system fit is employed and discussed in more detail.
} 
Specifically, payment system fit substitutes the simulated payment that a plan would receive for enrolling an individual for the regression predicted value. If $r_{j}$ is the revenue associated with person $j$ in a payment system and $c_{j}$ is the person's cost, the "payment system fit" is $\frac{\operatorname{Var}\left(c_{j}\right)-\operatorname{Var}\left(c_{j}-r_{j}\right)}{\operatorname{Var}\left(c_{j}\right)}$. This is analogous to an R-squared and is in fact equal to the R-squared if risk adjustment is the only factor determining plan payment.

Evaluating Payment Alternatives: Insurer-Level Risk

Our second measure relies on simulations to assess risk at the insurer level, noting that an insurer may offer multiple plans in the same and different markets. To assess the risk of losses under alternative payment methodologies we use simulation methods developed in Layton, McGuire, and Sinaiko (2016). We simulate the entire distribution of gains/losses and focus on the probability of a catastrophic loss, which we define as occurring when the average realized cost of a set of enrollees exceeds the averaged realized revenues by more than $5 \%$. ${ }^{29}$ We refer to the probability of a catastrophic loss as the "risk of ruin."

Let $\pi_{j}=r_{j}-c_{j}$ be the profits an insurer earns on a given individual, which could be positive or negative, depending on the form of the payment system. We define revenues as being equal to premiums plus transfer payments: $r_{j}=P+Y_{j}$, where we define individual payments, $Y_{j}$, analogously to payments $Y_{\mathrm{i}}$. As above, we assume that the premium is equal to the average cost in the data, $\mathrm{P}=\overline{\mathrm{C}}$, as it would be under perfect competition.

We simulate the distribution of revenues using a Monte Carlo simulation. Specifically, we take 10,000 random draws (with replacement) of $\mathrm{N}$ individuals from the data, where $\mathrm{N}$ is insurer size. Each random draw represents a potential set of enrollees. For a particular draw, k, we find the average cost of the selected enrollees, $\overline{\mathrm{c}}_{\mathrm{k}}$, and the average revenue, $\overline{\mathrm{r}}_{\mathrm{k}}$, allowing us to also compute the average profits, $\bar{\pi}_{\mathrm{k}}$.

We consider insurer sizes of 5k, 10k and 20k enrollees. Although there is no publicly available information about the distribution of enrollment levels at plans, it is known that there are many small insurers. ${ }^{30}$ While there are also many plans offered by very large insurers, these issuers

\footnotetext{
${ }^{29}$ We chose $5 \%$ as the threshold in order to ensure that there would be a sufficient number of "ruinous" draws of enrollees to be observable given the 10,000 draws we use in our simulations. Different thresholds would produce similar results in terms of the ranking of the alternative models of payment.

${ }^{30}$ For example, the 2017 Payment Notice contained special payment rules for plans with 500 or fewer billable member months statewide which was "approximately 125 issuers in 2014." (81FR 12237)
} 
are largely protected from risk by virtue of their size. Because it is the small issuers that reinsurance is designed to protect, we focus on them exclusively throughout the analysis. For each insurer size, we determine the portion of random draws for which average losses (negative profits) exceed 5\% of the average cost in the population, our measure of the "risk of ruin" under each payment system alternative. We use the same 10,000 random draws for all the payment alternatives studied for a given plan size. In this way, differences in the estimates of the risk of ruin are attributable to the differences in the properties of the payment system, not the luck of the draw.

\section{Empirical Results}

Table 1 contains some descriptive statistics on the $2 \mathrm{~m}$ observations in our 2013 sample. The mean spending in the sample was $\$ 5,059$ whereas the median was only $\$ 993$, an indication of the expected high degree of skewness in the distribution of annual spending. Although we focus only on total spending in this paper, we show in Table 1 the means for three major components of spending (inpatient, outpatient and drug), and the annual prevalence of selected chronic conditions as well as the prevalence of any chronic condition with chronic conditions defined as having at least one diagnosis that maps to the diagnoses assigned to a condition by the Clinical Classifications Software (CCS) codes developed by the Agency for Healthcare Research and Quality. ${ }^{31}$

\section{Prevalence of High-Cost Cases and Person-Level Profits and Losses}

The few very high cost patients account for a large share of annual costs. In our sample of $2 \mathrm{~m}$ people, the highest-cost person incurred costs of $\$ 4,563,813$. The $99^{\text {th }}$ percentile of spending was $\$ 67,393$ and above. This one percent of the population accounted for $28 \%$ of the costs. The top 10 percent of the population, those spending more than $\$ 10,537$, accounted for $70 \%$ percent of all spending. The average spending in the top decile was $\$ 35,175$, more than 35 times the median spending.

To anticipate how reinsurance or other policies addressing high-cost enrollees would affect the distribution of plan liabilities net of payments, Table 2 reports for four alternative attachment

\footnotetext{
31 Agency for Healthcare Research and Quality, Users guide: https://www.hcupus.ahrq.gov/toolssoftware/ccs/CCSUsersGuide.pdf. The CCS categories are more inclusive of diagnostic codes than the indicators used in the HHS-HCC risk adjustment model. See Montz et al (2016) for analysis of the payment implications of limited inclusion of behavioral health variables in the HHS-HCC categorization.
} 
points ( $\$ 100 \mathrm{k}, \$ 500 \mathrm{k}, \$ 1 \mathrm{~m}$ and $\$ 2 \mathrm{~m}$ ) the share of people and the share of (covered) spending above the attachment point. The coinsurance rate is $80 \%{ }^{32}$ The lowest attachment point of $\$ 100 \mathrm{k}$ affects only about one-half of one percent of enrollees. The share of the population touched by reinsurance with higher attachment points is very small, only .02\% and $.002 \%$ of the population for attachment points of $\$ 500 \mathrm{k}$ and $\$ 1 \mathrm{~m}$, respectively. In other words, an attachment point of $\$ 500 \mathrm{k}$ affects only 2 in 10,000. The $\$ 2 \mathrm{~m}$ attachment point is reached by only 3 people in our entire sample of $2 \mathrm{~m}$. While the numbers in the high range of attachment points are small and subject to sampling error, they are quite close to the rates reported by a private reinsurer based on its data for $2011 .^{33}$

The share of dollars covered by reinsurance is larger than the share of people affected for all attachment points. By dollars affected we mean $80 \%$ of spending above the specified attachment point. At an attachment point of $\$ 100 \mathrm{k}$, almost $10 \%$ of the spending is affected. The high attachment point of $\$ 1 \mathrm{~m}$ affects $0.2 \%$ of spending.

Like reinsurance, risk adjustment transfers funds from low to high-cost cases. After estimation of the risk score for each individual based on the HHS-HCC model, we compute the net plan liability post-risk adjustment as the difference between actual spending and the spending predicted by risk adjustment. The mean of this net plan liability variable is zero because we assume the average premium equals average cost. The few high-cost cases continue to impose plan losses, even with risk adjustment. Figure 1 presents average profits after risk adjustment by selected percentiles of spending. Plans lose, on average, $\$ 69,787$ for persons in the top $1 \%$ of spenders. Figure 1 shows that most enrollees are profitable: plans make money on all enrollees up through the $80^{\text {th }}$ percentile of spending. Risk adjustment leads to a nearly flat distribution of profits of around $\$ 2 \mathrm{k}$ per person from the $1^{\text {st }}$ to the $60^{\text {th }}$ percentile of the spending distribution.

Person-Level Fit: Payment System Fit

\footnotetext{
32 Recall that a coinsurance rate of $80 \%$ means that the insurer pays $20 \%$ of costs about the threshold and the reinsurance policy reimburses them for the other $80 \%$.

33 This private reinsurer reported rates exceeding $\$ 1 \mathrm{M}$ and $\$ 2 \mathrm{M}$ to be 25.3 and 2.1 per million lives for 2011. Our numbers in per million terms are 23.5 and 1.5. See http://www.munichhealthnare.com/newsletter/MHNA Newsletter Fall 2012.pdf, page 6. Note, however, that the text following the table reporting rates contains errors. The text mistakenly refers to the $2.1 /$ million as a $2.1 \%$ rate.
} 
Figure 2 presents payment system fit at the person level for our set of alternative payment systems. Precise values of the payment system fit measure are presented in Appendix Table A1. The "risk adjustment only" value of .438 is simply the R-squared from the conventional risk adjustment regression, and approximates the fit of the payment system for 2017 and beyond that would rely on risk adjustment with no reinsurance to match payments to costs at the person level. ${ }^{34}$ The Current System adds conventional reinsurance at alternative attachment points (all with coinsurance of .8) to risk adjustment. The figure shows that even the high attachment points of $\$ 1 \mathrm{~m}$ and $\$ 2 \mathrm{~m}$ which affect only a very small number of people improve fit over the risk adjustment only case. This is due to the concentration of the squared residuals at the top of the spending distribution. The $\$ 1 \mathrm{~m}$ attachment point with conventional reinsurance improves payment system fit to .496. Reducing the attachment point to $\$ 500 \mathrm{k}$ and $\$ 100 \mathrm{k}$ boosts payment system fit to .565 and .701 respectively. The effect of reinsurance on fit at the person level accelerates as the attachment point is lowered, as a larger share of the population is affected, and, for a given population, a larger share of costs are covered.

The figure also shows that modifying either the transfer formula (to (4')) or modifying the risk adjustment formula (to 3"') further improves payment system fit over conventional reinsurance, but these improvements are small (and, for the case of the modified transfer formula, do not even show up in three significant digits in the case of modifying the transfer formula for all but the lowest attachment point). In any comparison of conventional reinsurance, a modified transfer formula or reoptimized risk adjustment, the reoptimized risk adjustment must win on the criterion of payment system fit, by properties of least-squares estimators. This is borne out in the results presented in Figure 2. In the context of a modified risk adjustment formula, payment system fit is simply the Rsquared from a least-squares regression. Because least-squares maximizes the R-squared, any other weights on the variables must diminish the fit.

\section{$\underline{\text { Risk of Ruin }}$}

Tables 3a-3c compare the risk of ruin (the probability of realized costs exceeding revenues by $5 \%$ or more) for alternative payment methodologies for insurers with $20 \mathrm{k}, 10 \mathrm{k}$ and $5 \mathrm{k}$ members.

\footnotetext{
${ }^{34}$ This R-squared is slightly higher than the .3905 reported for the risk adjustment model estimated for the platinum adult plan (the closest comparison to our analysis) on MarketScan data from 2012 reported in the Payment Notice for 2017 (81 FR 12229). Our data are one year later, and also selected from the full MarketScan sample. We did not alter the regression coefficients to ensure monotonicity with disease categories, and any such modification from OLS estimates will diminish fit.
} 
With risk adjustment only, the risk of ruin for an insurer with $20 \mathrm{k}$ members is $1.1 \%$ per year. The $1.1 \%$ figure is determined by taking a random draw of $20 \mathrm{k}$ members from our $2 \mathrm{~m}$ person sample 10,000 times, and checking the profits/losses the plan would make with that draw and being paid by risk adjustment only. $1.1 \%$ of the time, the plan loses at least $5 \%$ of revenues. Table 3 a describes how the payment system alternatives mitigate this risk. Starting in the top-left cell of the table, the current system with a conventional separate reinsurance component reduces the risk of ruin slightly for a $\$ 2 \mathrm{~m}$ attachment point. Moving to the right in the same row, as the attachment point is lowered, the risk falls, until at the lowest attachment point of $\$ 100 \mathrm{k}$, it falls to $0.1 \%$. Reading down the columns, the risk of ruin is essentially unchanged by incorporating the reinsurance function in the transfer formula or the risk adjustment model.

The risk of ruin is considerably higher for an insurer with $10 \mathrm{k}$ members, $5.4 \%$ with risk adjustment only, as shown in Table 3b. The attachment point, as opposed to the method by which it is employed, is again the more important dimension in terms of the impact on the risk of ruin. The $2 \mathrm{~m}$ attachment has little effect. A $\$ 500 \mathrm{k}$ attachment point lowers the risk of ruin to about $3.0 \%$ for all payment alternatives. The lowest attachment point lowers the risk to $1.0 \%$ or less.

Finally, Table $3 \mathrm{c}$ depicts the risk of ruin for payment alternatives for a small insurer, with only $5 \mathrm{k}$ lives. To allow for visual comparison of the payment system alternatives, we also present these results in Figure 3. With risk adjustment only, an insurer of this size runs a risk of ruin of $11.4 \%$, which is reduced only slightly with a $\$ 2 \mathrm{~m}$ attachment point. It is worth noting here that the reinsurance function has two effects on profits that work in different directions. The payout with reinsurance must be financed with a payment on behalf of every insurer enrollee. The payment is equal to the expected payout in the full population. For the $\$ 2 \mathrm{~m}$ attachment point the payment is small, but non-trivial: $\$ 3.04$. When the payout is very rare, as it is with a $\$ 2 \mathrm{~m}$ attachment point, even 10,000 draws may not ever include any of the very few people spending more than $\$ 2 \mathrm{~m}$. When this is true, the only effect the simulations will pick up is the payments the plan must make per enrollee. These paymentd also of course are small, but on balance a rarely activated reinsurance policy (or its equivalent) may look worse than a payment system with no reinsurance in a simulation unless a very large number of simulations are run. This is not necessary, however, to appreciate the main point, which is that a very high attachment point will have a negligible effect on the risk of ruin, or more generally, on the distribution of profit outcomes for an insurer. 
Lowering the attachment point decreases the risk of ruin by increasing increments for the small insurer size in Figure 3. The figure also indicates that modifying the risk adjustment model performs slightly better than modifying the transfer formula, especially with lower thresholds. With respect to the risk of ruin, there was no guarantee that modifying the risk adjustment model would be superior to modifying the transfer formula as there was in the individual-level fit analysis above.

\section{$\underline{\text { Summary of Results }}$}

Lowering the attachment point (or its equivalent) has an accelerating effect on fit in both the individual-level and insurer-level analyses. Lowering has two effects: more people are picked up, and more of the costs are covered. The very high attachment point of $\$ 2 \mathrm{~m}$ touches a very small share of the population. The lowest attachment point studied, $\$ 100 \mathrm{k}$, with a large effect on fit at the person and insurer level, touches only one half of one percent.

The different ways to address high-cost cases - the current system with separate outlier payments, modifying the transfer formula, and modifying the risk adjustment model - all have effects of comparable magnitude given the same attachment point. Modifying the risk adjustment model is slightly superior to modifying the transfer formula which in turn is slightly superior to the current system with reinsurance figured separately.

Our results overstate the fit and risk protection that could be anticipated if any of these methodologies were put to use. Here, we estimate the risk adjustment model and simulate its performance on the same $2 \mathrm{~m}$ person sample. In practice, the estimation sample is distinct from the actual population to which the model and methodologies apply. There is no reason, however, to think the relative performance of the alternatives studied would not hold in a real application.

\section{Discussion}

State-level Marketplaces depend on robust plan supply and competition to put downward pressure on enrollee premiums and federal subsidies. The small scale of many local health insurance markets implies that effective competition requires participation by small insurers. Demise of the federally operated mandatory reinsurance for Marketplace plans shifts new risk to all insurers, but the effect on small insurers is particularly large. This increase in risk for small insurers implies that these insurers will either be required to dramatically increase their stock of reserves, increasing barriers to entry in this market, or purchase private reinsurance and pay the mark-ups and 
administrative costs that come with it. This will likely inhibit supply of smaller plans and potentially degrade competition in Marketplaces. Said another way, loss of reinsurance raises costs of small insurers relative to larger insurers, exacerbating economies of scale in insurance.

This paper considers alternatives for keeping the reinsurance function active within the current regulatory framework for Marketplace plan payment by modifying the transfer formula or by modifying the risk adjustment model itself. The modifications we consider provide better fit and insurer risk protection than the current approach with reinsurance payments figured independently of the risk adjustment components of payment. Design of the transfer formula or risk adjustment model taking account of reinsurance can do better than a plan payment methodology in which the presence of reinsurance is ignored. Our main message is thus an optimistic one: integrating the reinsurance function within other elements of the payment system is simple and feasible, and can improve the payment system performance. We first discuss the advantages and disadvantages of the form of modification and then the choice of attachment point.

Two comments apply to both routes of modification. First, both forms of modification, via the transfer formula or via the risk adjustment model, are easy to implement. Exhibit A for this argument is that we conducted multiple versions of both forms of modifications in the course of writing this paper, using an updated and selected version of the data used for development of the federal payment methodologies. Second, a big plus for either modification is the savings in transaction costs that will ultimately help to stabilize premiums. Although we did not find information about pricing of private reinsurance, obviating the need for small insurers to put contracts covering their high costs out to bid through brokers would likely represent a significant savings to insurers, decreasing both barriers to entry and consumer premiums (and, thus, also government subsidies) in this market.

Modifying the risk adjustment model has several key advantages over modifying the transfer formula. First, we believe modifying the risk adjustment model is more transparent and elegant than modifying the transfer formula. The analysis in Section 3 used a simplified version of the transfer formula to make an analytical point. In practice the over-worked transfer formula is very complicated, taking account of geographic cost differences, actuarial value differences, and demand response. By contrast, specification of the risk adjustment model is straightforward. Publication of the specification and estimated coefficients is routinely made available to interested parties by CMS. Furthermore, the risk adjustment route is readily generalizable, and could serve as a constructive model 
for other risk adjustment applications. Finally, because the risk adjustment coefficients are optimized in the presence of the payments for high-cost cases, the fit at the individual level must be superior to the fit from modifying the transfer formula method.

Turning to the issue of selecting an attachment point, not surprisingly, lower attachment points increase fit at the person level and risk protection at the insurer level. Our paper quantifies the accelerating effect of lowering the attachment point in the context of the Marketplace risk adjustment model. The main concern with setting a low attachment point is weakened incentives for cost control. Our analyses also inform to what degree an attachment point, such as $\$ 500 \mathrm{k}$ with an $80 \%$ coinsurance, diminishes a plan's incentives to control costs. As Table 2 shows, a trivial number of people $(0.02 \%)$ and a very small portion of the dollars $(1 \%)$ are affected by an attachment point at this level. Using either of these shares as a metric, a $\$ 500 \mathrm{k}$ attachment point can be seen as having a negligible effect on incentives.

Papers in the research literature check the effect of reinsurance on incentives, and compare reinsurance to concurrent risk adjustment in terms of incentive effects (Geruso and McGuire, 2016; Layton, McGuire, and Sinaiko 2016). Any diagnostic-based risk adjustment model weakens incentives to some degree since plans are paid more when their enrollees get some care than when they get no care, as a doctor visit must occur in order for diagnoses to be reported on claims. "Upcoding” of diagnoses is also a persistent problem with risk adjusted payment systems. The prospective risk adjustment model leads Medicare Advantage plans to up risk scores by about 6-7\% compared to traditional Medicare by some combination of more services and simple upcoding. (Geruso and Layton, 2015) Concurrent risk adjustment, as is used in Marketplaces, weakens incentives even more than the prospective systems that are used in Medicare Advantage (and virtually all other contexts world-wide). Concurrent risk adjustment also weakens incentives more than reinsurance with a $\$ 45 \mathrm{k}$ attachment point (Geruso and McGuire, 2016, Table 1).

In our view, concerns about incentives are negligible until the attachment point is $\$ 500 \mathrm{k}$ or less. If weak incentives for cost control are a concern for Marketplace plans, attention should be directed to the real culprit, concurrent risk adjustment, not reinsurance affecting a very small fraction of the covered lives.

As we point out above, reinsurance, as an explicit or implicit component of a plan payment methodology has the additional benefit of mitigating problems of adverse selection (Layton, Ellis 
and McGuire, 2015). The multiple-year high cost indicator was included within the Dutch risk adjustment formula with the purpose of discouraging plans from discriminating against likely highcost consumers (Van Kleef and Van Vliet, 2012). Our results regarding payment system fit indicate that inclusion of a new variable in risk adjustment equal to costs above a threshold as we study here would also reduce incentives for selection. Private reinsurance, by contrast, would not work to diminish selection incentives, since a plan subject to an adverse selection of the risks would have to pay for this through a risk-rated private premium.

A number of design choices, beyond the scope of this paper, would need to be addressed before the ideas considered here could be put into practice. We simulated the effect of a single national risk pool. A national policy would result in cross-subsidies from low intensity/low cost areas to high intensity/high cost areas, which would lower prices in high spending areas and raise prices in low spending areas. A state policy would not result in such subsidies (or would at least cause them to a lesser extent). Figuring pooling at a lower level of aggregation would limit or eliminate subsidies across geographic areas or types of plans. Additionally, if minimizing "risk of ruin" is the primary objective of a reinsurance policy, it might be optimal to vary the generosity of the reinsurance (or quasi-reinsurance) policy by plan size in order to better protect smaller plans that are more vulnerable to risk.

In summary, insurer risk is important in Marketplaces, having direct consequences on entry and exit decisions for both small and large insurers. There are ways to protect insurers against risk without having large effects on insurer incentives via the payment system already at work in these markets. The policy modifications we explore here reduce insurer risk more efficiently than similar private reinsurance market solutions because there are no mark-ups or administrative costs. The policies studied here also help with adverse selection problems beyond the reach of private reinsurance. 


\section{$\underline{\text { References }}$}

Armour, S. (2016), “Obama Administration Works to Fix Health Insurance Co-ops," Wall Street Journal, January 21.

Assistant Secretary for Planning and Evaluation (ASPE) (2015), "Competition and Choice in the Health Insurance Marketplaces, 2014-2015: Impact on Premiums,” ASPE Issue Brief, Department of Health and Human Services.

Assistant Secretary for Planning and Evaluation (ASPE) (2016), "Health Insurance Marketplace Premiums After Shopping, Switching, and Premium Tax Credits, 2015 - 2016,” ASPE Issue Brief, Department of Health and Human Services.

Brown, J., Duggan, M., Kuziemko, I., \& Woolston, W. (2014). “How Does Risk Selection Respond to Risk Adjustment? New Evidence from the Medicare Advantage Program,” The American Economic Review, 104(10), 3335-3364.

Center For Consumer Information \& Insurance Oversight (CCIIO) (2015), "Summary Report on

Transitional Reinsurance Payments and Permanent Risk Adjustment Transfers for the 2014

Benefit Year,” June 30, 2015, CCIIO, Centers for Medicare \& Medicaid Services.

Center For Consumer Information \& Insurance Oversight (CCIIO) (2016), "Discussion Paper"

Prepared for the HHS-Operated Risk Adjustment Methodology Meeting, March 31, 2016, CCIIO, Centers for Medicare \& Medicaid Services.

Consumers for Health Options, Insurance Coverage in Exchange States (CHOICES) (2015), “Technical Issues with ACA Risk Adjustment and Risk Corridor Programs, and Financial Impact on New, Fast-Growing, and Efficient Health Plans,” November.

GAO (Government Accounting Office) (2015), "Patient Protection and Affordable Care Act: Despite Some Delays, CMS has made Progress Implementing Programs to Limit Health Insurer Risk," GAO-14-447. Washington, DC, April.

Geruso, M. and Layton, T.J. (2015) “Upcoding: Evidence from Medicare on Squishy Risk Adjustment," NBER Working Paper \#21222

Geruso, M. and McGuire, T.G. (2016), "Tradeoffs in the Design of Health Plan Payment Systems: Fit, Power and Balance," Journal of Health Economics, (47): 1-19. 
Goodell, Sarah (2015), "Risk Corridors. An amendment to the 2015 federal budget continuing appropriation raises a question: Will insurers receive their full 2014 risk corridor payments?" Health Policy Brief, Health Affairs and Robert Wood Johnson Foundation, http://healthaffairs.org/healthpolicybriefs/brief pdfs/healthpolicybrief 134.pdf. Accessed May 18, 2016.

Kaiser Family Foundation (2013), "Individual Insurance Market Competition, 2013” and "Large Group Insurance Market Competition, 2013,” State Health Facts, http://kff.org/statecategory/health-insurance-managed-care/insurance-market-competitiveness/. Accessed May 19, 2016.

Kaiser Family Foundation (2014), "Explaining Health Care Reform: Risk Adjustment, Reinsurance, and Risk Corridors," Jan 22, 2014. http://kff.org/health-reform/issue-brief/explaininghealth-care-reform-risk-adjustment-reinsurance-and-risk-corridors/. Accessed May 19, 2016.

Kautter, J., Pope, G.C., Ingber, M., Freeman, S., Patterson, L., Cohen, M. and Keenan, P. (2014), "The HHS-HCC Risk Adjustment Model for Individual and Small Group Markets under the Affordable Care Act," Medicare \& Medicaid Research Review 4(3): E1-E11.

La Monica, Paul (2016), "UnitedHealthcare to Exit Most Obamacare Exchanges," CNN Money, http://money.cnn.com/2016/04/19/investing/unitedhealthcare-obamacare-exchangesaca/, April 19, 2016. Accessed May 16, 2016.

Layton, T., Ellis, R.P., and McGuire, T.G., (2015) “Assessing Incentives for Adverse Selection in Health Plan Payment Systems," National Bureau of Economic Research Working Paper 21531, September, 2015.

Layton, T., McGuire, T.G. and Sinaiko, A.S. (2016), "Risk Corridors and Reinsurance in Health Insurance Marketplaces: Insurance for Insurers” American Journal of Health Economics, 2(1): 66-95.

Massachusetts Health Connector, Reports and Publications, https://betterhealthconnector.com/about/policy-center/reports-publications. Accessed May 18, 2016.

McGuire, T.G., Glazer, J., Newhouse, J.P., Normand, S-L., Shi, J., Sinaiko, A.D. Zuvekas, S. (2013) "Integrating Risk Adjustment and Enrollee Premiums in Health Plan Payment," Journal of Health Economics 32(6): 1263-1277. 
McGuire, T.G., Newhouse, J.P., Normand, S-L., Shi, J. and Zuvekas, S. (2014) "Assessing Incentives for Service-Level Selection in Private Health Insurance Exchanges," Journal of Health Economics 35: 47-63.

Montz, E., Layton, T., Busch, A., Ellis, R., Layton, T. Rose, S. and McGuire, T. (2016) "Risk Adjustment Simulation: Plans May Have Incentives to Distort Mental Health and Substance Use Coverage," Health Affairs, 35(6): 1022-28.

Pope, G.C., Bachofer, H., Pearlman, A., Kautter, J., Hunter, E., Miller, D. and Keenan, P. (2014) "Risk Transfer Formula for Individual and Small Group Markets Under the Affordable Care Act," Medicare \& Medicaid Research Review 4(3): E1-E23.

PwC (2016), "Three Years In, the ACA Marketplace Shows Modest Premium Growth, Fewer Plan Options, and Continued Competition," Health Research Institute, PwC, http://pwchealth.com/cgi-local/hregister.cgi/reg/pwc-hri-ACA-exchange-analysisbooklet.pdf. Accessed May 18, 2016.

Rose, S., Shi, J., McGuire, T.G. and Normand, S-L. (forthcoming) "Matching and Imputation Methods for Risk Adjustment in Health Insurance Exchanges," Statistics in Biomedical Sciences.

Schillo, S., G. Lux, J. Wassem and F. Buchner (2016) "High Cost Pool or High Cost Groups - How to Handle Highest Cost Cases in a Risk Adjustment Mechanism?” Health Policy (120): 141147.

Schmid, C. and K. Beck (forthcoming) "Re-insurance in the Swiss Health Insurance Market: Fit, Power and Balance," Health Policy.

Swartz, K. (2006) Reinsuring Health: Why More Middle-Class People are Uninsured and What the Government Can Do, New York: Russell Sage Foundation.

Van Barneveld, E., L. Lamers, R. Van Vliet and W. Van de Ven (1998), "Mandatory Pooling as a Supplement to Risk Adjusted Capitation Payments in a Competitive Health Insurance Market," Social Science and Medicine, (47): 223-32.

Van Barneveld, E., L. Lamers, R. Van Vliet and W. Van de Ven (2001), "Risk Sharing as a Supplement to Imperfect Capitation: A Tradeoff Between Selection and Efficiency,” Journal of Health Economics 20(2): 147-168.

Van Kleef, R. C. and R. van Vliet (2012), "Improving Risk Equalization Using Multiple-Year High Cost as a Health Indicator," Medical Care 50(2): 140-144. 
Zhu, J.M., Layton, T.J., Sinaiko, A.D. and McGuire T.G. (2013) “'The Power of Reinsurance in Health Insurance Exchanges to Improve the Fit of the Payment system and Reduce Incentives for Adverse Selection," Inquiry 50(4): 255-75. 
Figure 1: Profits/Losses by Selected Percentiles of Spending, Risk Adjustment Only

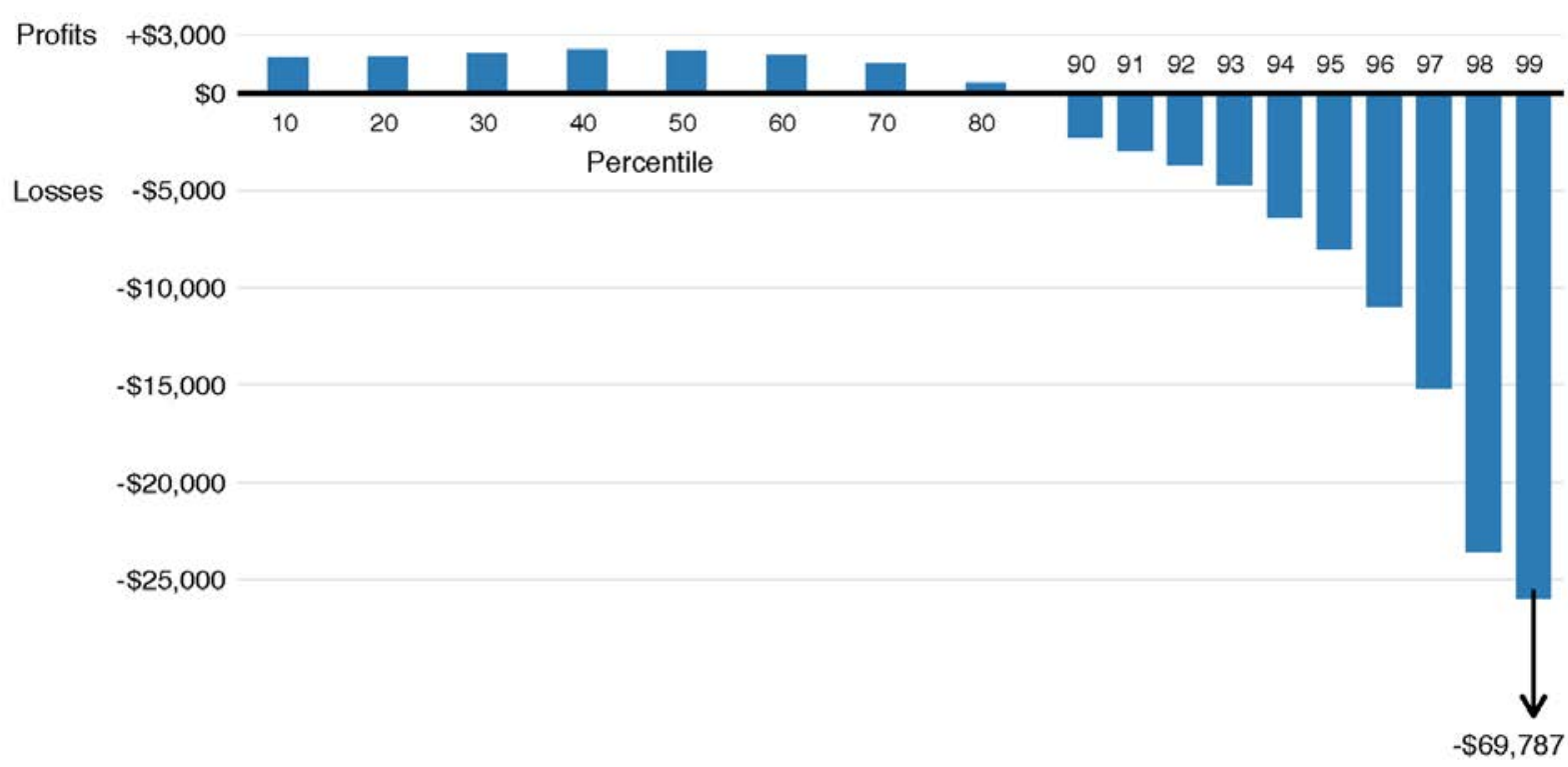

Notes: The figure presents average profits for each decile/percentile of spending. Profits are equal to simulated revenues minus costs. Simulated revenues are based on the HHS transfer formula and incorporate risk adjustment but not reinsurance (or the reinsurance alternatives we present in the paper). 
Figure 2: Payment System Fit for Alternative Payment Systems

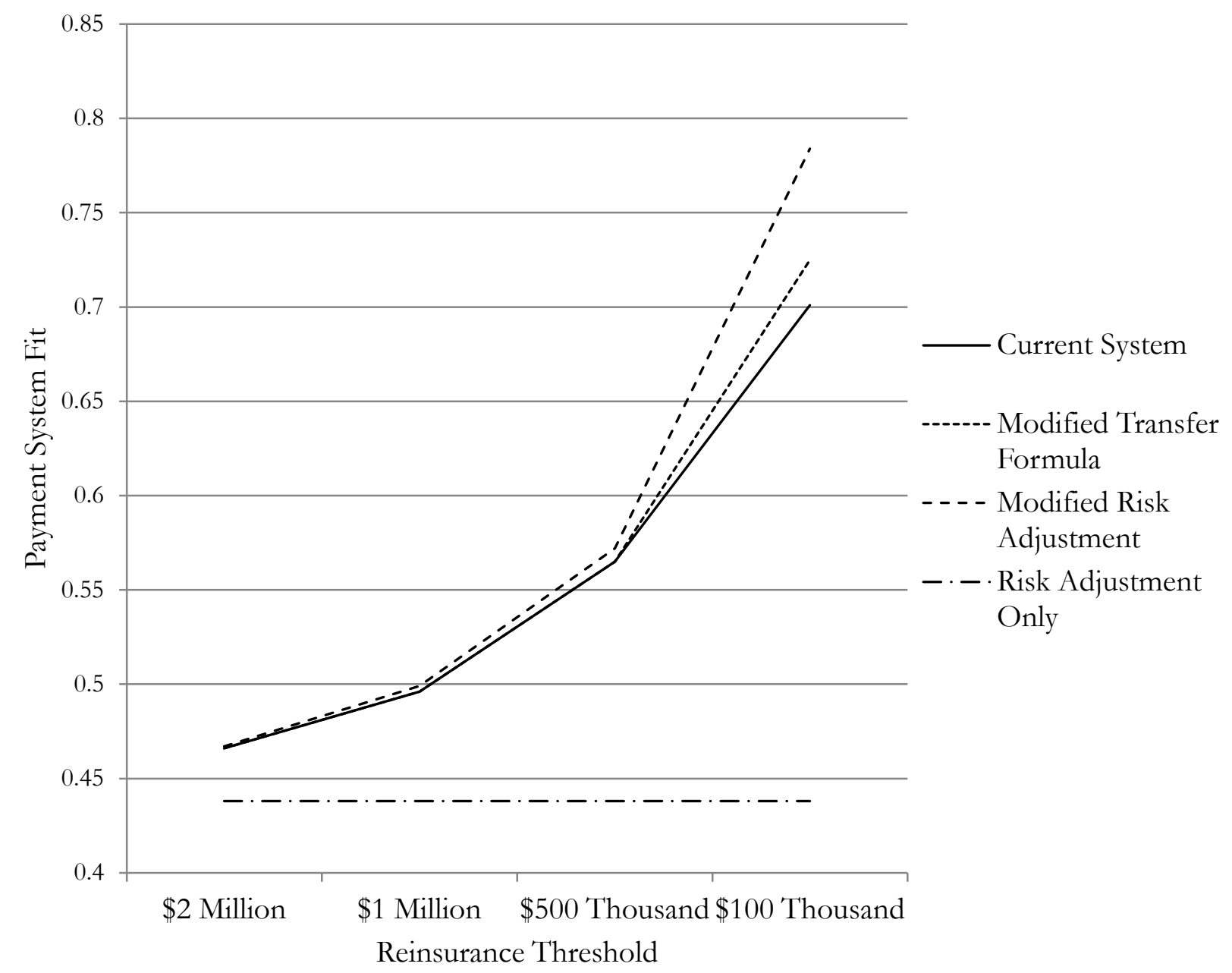

Notes: The figure presents payment system fit for each of the alternative payment systems for four thresholds. Payment system fit is defined as the R-squared from a regression of costs on simulated revenues under the payment system. Under the current system, the payment system incorporates risk adjustment and conventional actuarially fair reinsurance. Under the modified transfer formula, reinsurance is incorporated via the transfer formula. Under modified risk adjustment, reinsurance is incorporated via the risk adjustment formula. 
Figure 3: Risk of Ruin for an Insurer with 5,000 Enrollees under Alternative Payment Systems

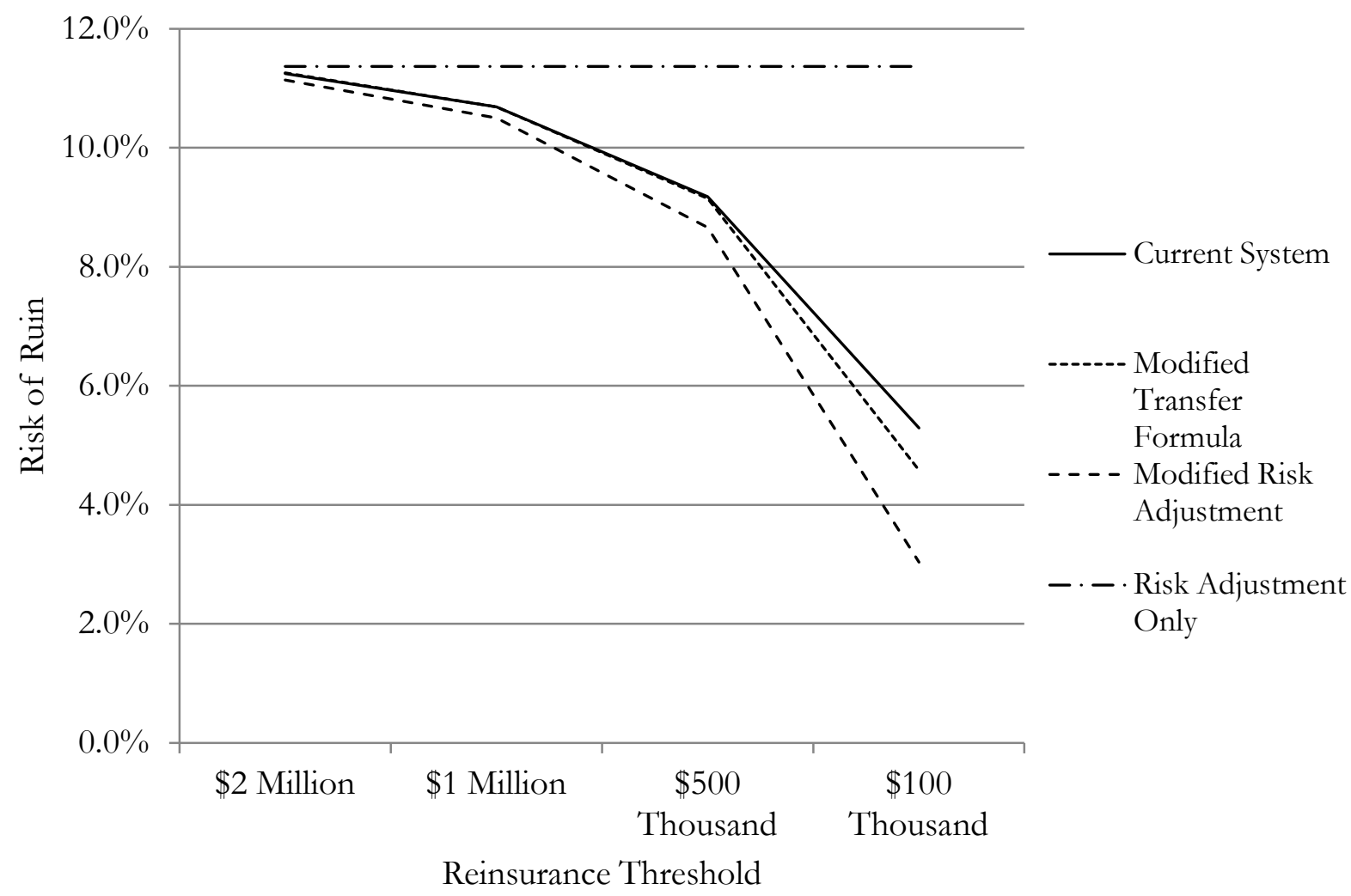

Notes: The figure presents the "risk of ruin" for an insurer with 5,000 enrollees under a variety of alternative payment systems. Risk of ruin is calculated via simulation. First, we take 10,000 draws of 5,000 individuals from our sample. For each draw, we calculate the average profits/losses for the draw as the difference between average simulated revenue and average cost. We then calculate the portion of draws for which the average loss exceeded 5\% of average cost. This percent is the risk of ruin. Revenues were simulated separately for each payment system alternative. Under the current system, the payment system incorporates risk adjustment and conventional actuarially fair reinsurance. Under the modified transfer formula, reinsurance is incorporated via the transfer formula. Under modified risk adjustment, reinsurance is incorporated via the risk adjustment formula. 
Table 1: Summary Statistics for Marketplace Sample (means are reported unless otherwise noted)

\begin{tabular}{lrc} 
N & & $2,006,126$ \\
Age & & 42.40 \\
Female & & 0.49 \\
Census Region & & \\
& Northeast & 0.14 \\
& Central & 0.23 \\
& South & 0.43 \\
& West & 0.20 \\
Total Spending & & \\
& Mean & $\$ 5,059$ \\
& Median & $\$ 993$ \\
& 90 th Percentile & $\$ 10,537$ \\
& 95 th Percentile & $\$ 20,153$ \\
99th Percentile & $\$ 67,393$ \\
Inpatient Spending & Max & $\$ 4,563,813$ \\
Outpatient Spending & & $\$ 1,357$ \\
Drug Spending & & $\$ 2,779$ \\
One or More Chronic Conditions & $\$ 922$ \\
Cancer & & 0.33 \\
Heart Disease & & 0.07 \\
Mental Health & & 0.07 \\
Diabetes & & 0.11 \\
\hline
\end{tabular}

Notes: The table includes summary statistics describing our sample of individuals from the 2013 Truven MarketScan data that were chosen to match the demographics, geography, and illness patterns of individuals eligible for Marketplace plan enrollment. An individual is defined as having a chronic condition if she has at least one diagnosis for that condition during 2013. 
Table 2: Shares of Spending and People above Attachment Points

\begin{tabular}{lcccc}
\hline Attachment point & \$2 Million & \$1 Million & \$500 Thousand & \$100 Thousand \\
\hline Number above cutoff & 3 & 47 & 406 & 10608 \\
Percent of People above Cutoff & $0.0002 \%$ & $0.002 \%$ & $0.020 \%$ & $0.530 \%$ \\
Share of dollars & $0.060 \%$ & $0.222 \%$ & $1.012 \%$ & $9.953 \%$ \\
\hline
\end{tabular}

Notes: The table presents statistics describing high cost cases in our sample. Each column shows the number of people above a cutoff, the percent of people above a cutoff, and the share of dollars covered by reinsurance for a given cutoff. The "attachment point" is the cutoff. 
Table 3a: Risk of Ruin -- Insurer Size 20k

\begin{tabular}{lcccc}
\hline Attachment Point & \$2 Million & \$1 Million & \$500 Thousand & \$100 Thousand \\
\hline Current System & $0.9 \%$ & $0.7 \%$ & $0.4 \%$ & $0.1 \%$ \\
Modified Transfer Formula & $0.9 \%$ & $0.8 \%$ & $0.4 \%$ & $0.0 \%$ \\
Modified Risk Adjustment & $0.9 \%$ & $0.8 \%$ & $0.4 \%$ & $0.0 \%$ \\
Risk Adjustment Only & & & $1.1 \%$ & \\
\hline
\end{tabular}

Table 3b: Risk of Ruin -- Insurer Size 10k

\begin{tabular}{lcccc}
\hline Attachment Point & $\$ 2$ Million & $\$ 1$ Million & \$500 Thousand & \$100 Thousand \\
\hline Current System & $5.0 \%$ & $4.2 \%$ & $3.0 \%$ & $1.0 \%$ \\
Modified Transfer Formula & $5.0 \%$ & $4.2 \%$ & $3.0 \%$ & $0.7 \%$ \\
Modified Risk Adjustment & $4.9 \%$ & $4.3 \%$ & $3.1 \%$ & $0.3 \%$ \\
Risk Adjustment Only & & & $5.4 \%$ & \\
\hline
\end{tabular}

Table 3c: Risk of Ruin -- Insurer Size 5k

\begin{tabular}{lcccc}
\hline Attachment Point & $\$ 2$ Million & \$1 Million & $\$ 500$ Thousand & \$100 Thousand \\
\hline Current System & $11.3 \%$ & $10.7 \%$ & $9.2 \%$ & $5.3 \%$ \\
Modified Transfer Formula & $11.3 \%$ & $10.7 \%$ & $9.2 \%$ & $4.6 \%$ \\
Modified Risk Adjustment & $11.1 \%$ & $10.5 \%$ & $8.7 \%$ & $3.0 \%$ \\
Risk Adjustment Only & & & $11.4 \%$ & \\
\hline
\end{tabular}

Notes: The tables present the "risk of ruin" for each payment system for insurers with varying number of enrollees. "Risk of ruin" is defined as the probability that an insurer will enroll a set of individuals that results in a loss of greater than $5 \%$ of revenues. To calculate the risk of ruin, we take 10,000 random samples of $\mathrm{N}$ individuals (where $\mathrm{N}$ is equal to insurer size) and calculate the percent of the 10,000 samples where the average cost exceeds the average cost in the full population by at least $5 \%$. 
Appendix 
Table A1: Payment System Fit under Alternative Payment Systems

\begin{tabular}{lcccc}
\hline Attachment Point & \$2 Million & \$1 Million & \$500 Thousand & \$100 Thousand \\
\hline Current System & 0.466 & 0.496 & 0.565 & 0.701 \\
Modified Transfer Formula & 0.466 & 0.496 & 0.565 & 0.725 \\
Modified Risk Adjustment & 0.467 & 0.499 & 0.572 & 0.784 \\
Risk Adjustment Only & & \multicolumn{3}{c}{0.438} \\
\hline
\end{tabular}

Notes: The table presents estimates of "payment system fit" for each simulated payment system. Payment system fit is the "fit" or R-squared statistic from a regression of spending on simulated revenues for a given payment system. "Current System" refers to a payment system with concurrent risk adjustment and a conventional reinsurance policy where reinsurance payments are funded by an actuarially fair per capita premium. "Modified Transfer Formula" refers to a payment system where the transfer formula is modified such that it generated payments equivalent to those generated by the "Current System." "Modified Risk Adjustment" refers to a payment system where the risk score incorporates reinsurance. 